\title{
Slipped Disc: Developing M-Health Apps to Promote Awareness among Malaysian Society
}

\author{
Dahlan Bin Abdul Ghani, Muhammad Farhan Abd Jalil, Luqman Zulhilmi Bin Abdul 'Alim
}

\begin{abstract}
- starting late, back torment is brisk transforming right into a disease wherein there's no obstruction. In Malaysia, basically $60 \%$ and eighty\% of humans will experience low back torment ultimately of their lives. A slipped circle generally called a prolapsed or herniated plate, occurs while one of the circles that take a seat between the bones of the backbone (the vertebrae) is hurt and pushes on the nerves. the reason at the back of this investigation is to raise the nature with slipped hover among Malaysian way of life due to the nonattendance of prologue to the overall population approximately the hazard of herniated plate or broadly speaking referred to as as slipped circle might also reason a real case that relate to this sickness. To acquire the objective of this assessment, we have went with an association to develop a mobile cellphone application which it's miles a savvy and straightforward software. We believe that this research will supply a foremost information approximately slipped hover diseases by means of giving an statistics on oneself idea measures in like manner assist them to realize it into their education.
\end{abstract}

Watchwords: slipped circle, prolapsed, herniated plate, beneficial, care, cell telephone, android utility.

\section{INTRODUCTION}

Decrease returned torment is an amazingly important trouble, with approximately eighty\% of the loads questioning lower back distress in some unspecified time in the future or every other in their lives. In approximately $23 \%$ of times, it transforms right right into a longstanding problem, while in five $\%$, it sooner or later finally ends up crippling as communicated in Malaysia's massive name online Newspaper (August, 2012). Low again torment further is the second maximum compelling motivation for work nonattendance, after the standard contamination. Low again distress (LBP) has ended up being one of the most certified fashionable healing issues, with a whole existence occurrence as high as 83.Nine\% (Balague et.Al, 2012). The considerable majority of low returned torment instances is relied upon to non-unique motives, and most guarantee all of a sudden. Some of the illnesses related to low returned torment is slipped circle. An atypical nation of human beings may have low decrease lower back torment and leg executed by means of way of a slipped circle. A slipped hover goes by using a good sized scope of names. It's miles

Revised Manuscript Received on September 10, 2019.

Dahlan Bin Abdul Ghani, Universiti Kuala Lumpur (UniKL), Malaysian Institute of Information Technology, 1016 Jalan Sultan Ismail, 50250 Kuala Lumpur, Malaysia.

(E-mail: dahlan@miit.unikl.edu.my)

Muhammad Farhan Abd Jalil, , Universiti Kuala Lumpur (UniKL), Malaysian Institute of Information Technology, 1016 Jalan Sultan Ismail, 50250 Kuala Lumpur, Malaysia.

(E-mail: Farhan@unikl.edu.my)

Luqman Zulhilmi Bin Abdul 'Alim, Faculty of Creative Media, Limkokwing University, Inovasi 1-1, Jalan Teknokrat 1/1, 63000 Cyberjaya, Malaysia.

(E-mail: luqmanzulhilmi999@yahoo.com) called a herniated plate, a prolapsed circle, or a jutting plate. Herniated circle seem while gel-like spinal plate middle bursts thru a mild vicinity inside the outrageous outer divider which resembles the filling being squashed. Decrease lower back or leg torment, shuddering, or deadness may takes place at a few issue element circle material collides with spinal nerves. The underlying improve of restoration remedy fuses relaxation, torment tranquilize, spinal combos and bodily theraphy. Anyhow, if the symtomps could not mild, it's far endorsed to stumble upon restorative method to oust the wrong region. This evaluation is revolve around slipped circle and the perceive of this examination is The Experimental of evaluation cellular Apps for Slipped Disk amongst Malaysia. The foundation riding this assessment is to make the care about Slipped Disk contamination among Malaysia society. In Malaysia, slipped plate contamination has been at the rising. Twenty years again, slip circle or herniated plate a good buy of the time hop out on the individual as laborer or step by step prepared, no greater, the estimations show up, 20 percentage of youths developed some area in the scope of 9 and eleven years within the u.S.A. Of the usa face the problem of slip hover as communicated via Dr. Yama Zafer who's creator and planner of NSD therapy at Chiropractic Speciality center. He communicated that the usa has returned to - torment as 'the accompanying scourge'. He in like manner communicated that "it's miles proper now the most actual healing hassle in the world, and it is seen because the number one wellspring of inadequacy in human beings greater younger than forty five". It's far crucial to ensure the prosperity and thriving of Malaysians thru bodily activities to propel the cognizance of Slipped plate sickness from viewpoint of social development. Dismissing the way that a slipped plate can now and again be astoundingly horrendous, a first-rate variety people sense higher with just a large a part of a month or month of non-cautious remedy. There multiple variables that contributes within the path of problem inner this research, for example, poor consciousness approximately slipped hover ailment amongst Malaysia society. The predisposition among Malaysia society approximately slipped plate have cause them the absence of fear towards slipped hover sickness with Ignorant in self-care measure from slipped circle sickness. Self-care the directors acquire a major profession within the useful time of the illness. Workout, food plan, stress, and weight all impact lower back torment. Changing sure way of life elements can assist abatement, and likely foresee, lower back misery. Taking the entirety into attention, there

Published By:
Blue Eyes Intelligence Engineering \& Sciences Publication 
nonetheless nonattendance of modernized attempt to improvement "slipped plate" infection the diverse Malaysian life-style. No matter the way that slipped plate disorder have been on the climb on this u.S., there's nonetheless no incredible propelled attempt (, as an instance, television industrial, virtual Billboards, web marketing) specifically that may be efficaciously scattered or any marketing campaign that submitted highly to make the care approximately the threat of slipped circle.

Thusly, observational affirmation prescribes that customers reply to a noteworthy piece of the publicizing at the net in indistinct processes from they reply to advancing in normal media, in any occasion with appreciate to standard extents of publicizing ampleness. Net and specific automatic canny media like tv or flexible software were even extra winning, responsive, and flexible than full-size media (Pavlov, 1999). The development of the present day systems need to be suitable with human point of confinement of correspondence and headways are relied upon to skip on the point of interest of this sickness. This assessment has covered the importance of Slipped Disk and the nonattendance of care regarding this disease amongst the overall populace in Malaysia. Slipped Disk need to be targeted on in slight of the manner that slipped plate is a precarious disease, the notable component is to hold up a critical proper strategies from the ailment. As installed by using the usage of Adrian et.Al (2000), mobile figuring has snatched the attention of the assessment set up for pretty a while and has further landed at the organisation and elegant clients by means of way of methods for telephones and PDAs. Greater than ever, such devices can run wealthy loose programs further as surpassed on consumer server programs that passageway data through a web entry in particular in progressing restorative studying. With everything taken below attention, this bendy sensible utility is simple to them to enable them to see signs and symptoms and signs of slipped plate so that it will improve the case revelation of slipped circle, its underlying referral and on this manner diminishing dismalness and mortality of slipped plate in starting period.

\section{ASSOCIATED ART WORK}

Programs empowers human beings to get admission to references substances, restorative data and lab assessments through phones (Darrell, 2013). Bendy contraption gives numerous structures to assist with issues. There are streets in which social protection motion may be stepped forward through various beneficial packages. It is able to help reducing down the charges with the aid of way of empowering the challenge of belief and partner people to the social protection providers. Upgrades are used for humans encountering Alzheimer and dementia in cellular health Care packages containing GPS potential to pursue sufferers whereabouts. The person can be find out and move in to thoughts setting.

Spinal fitness Week 2016 will interest on pointers on how to perform and live better by using help their inner rival through incredible spinal restrict, diminishing torment, improving role and dealing with one's prosperity. Consistent with CAA (Chiropractors' association of Australia) net website (April, 2016), With the Olympics throughout the curve, the Chiropractors' affiliation of Australia should use the prevailing three hundred and sixty five days's Spinal health Week, held among 23-29 might also additionally, to remind all Australians they do not need to wave specialists to benefit height execution anyway each person can perform and stay higher by sponsorship their internal rival, thru remarkable spinal restriction, lessening torment, maintaining up sound position and coping with one's prosperity. Even as Rio 2016 will comprise in extra of 10,500 contenders from 206 countries, who are starting at now in focused getting geared up and chiropractic care to carry out to their final, the present year's Spinal fitness Week's back Your inner Athlete marketing campaign reminds all Australians that, sports activities contenders, but everybody, can again their own precise internal rival and perform to their pinnacle thru doing clean such things as focusing on the hugeness of spinal limit, reducing misery, supervising function, which, diagnosed with a strong life-style can help incite execution (April, 2016).

\subsection{Mobile Apps Related to Herniated Disk}
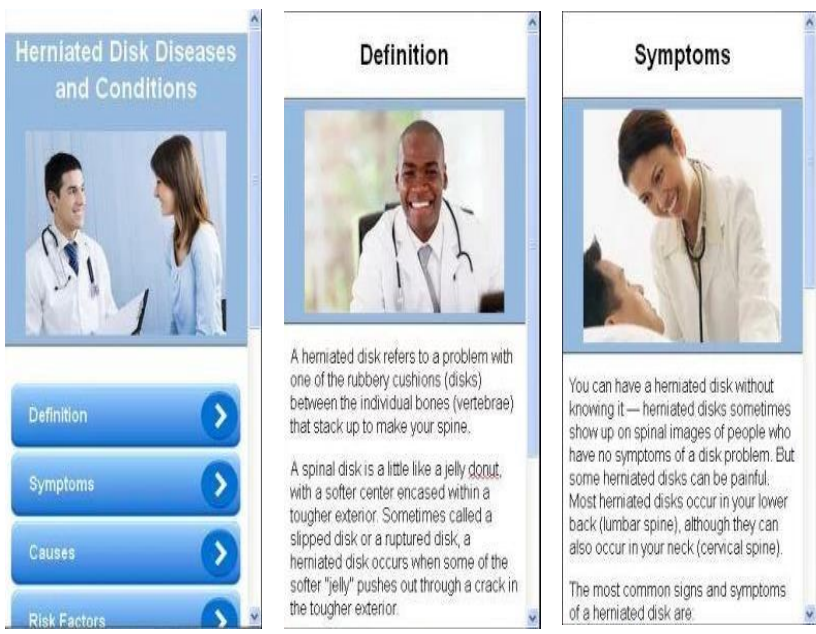

\section{Figure 1.0: The interface of Herniated Disk Information application}

Determine 1.0 above showcase the interface of Herniated Disk facts software. This application has been made to give the client data, care, motives, signs, influences slipped circle infirmities. This application makes feel of the way to supply an good enough and appropriate information on slipped plate contamination. The software furthermore does now not over-trouble the client with tangled healing wording, the language is apparent and does now not require any capability. Regardless, it does not give a maximum essential belief on what is simply the slipped plate sickness issue. There aren't any expertise segments that can impart the customer to maintain the use of this software. The interface of this application is in like way exorbitantly stupid and no longer engaging. 

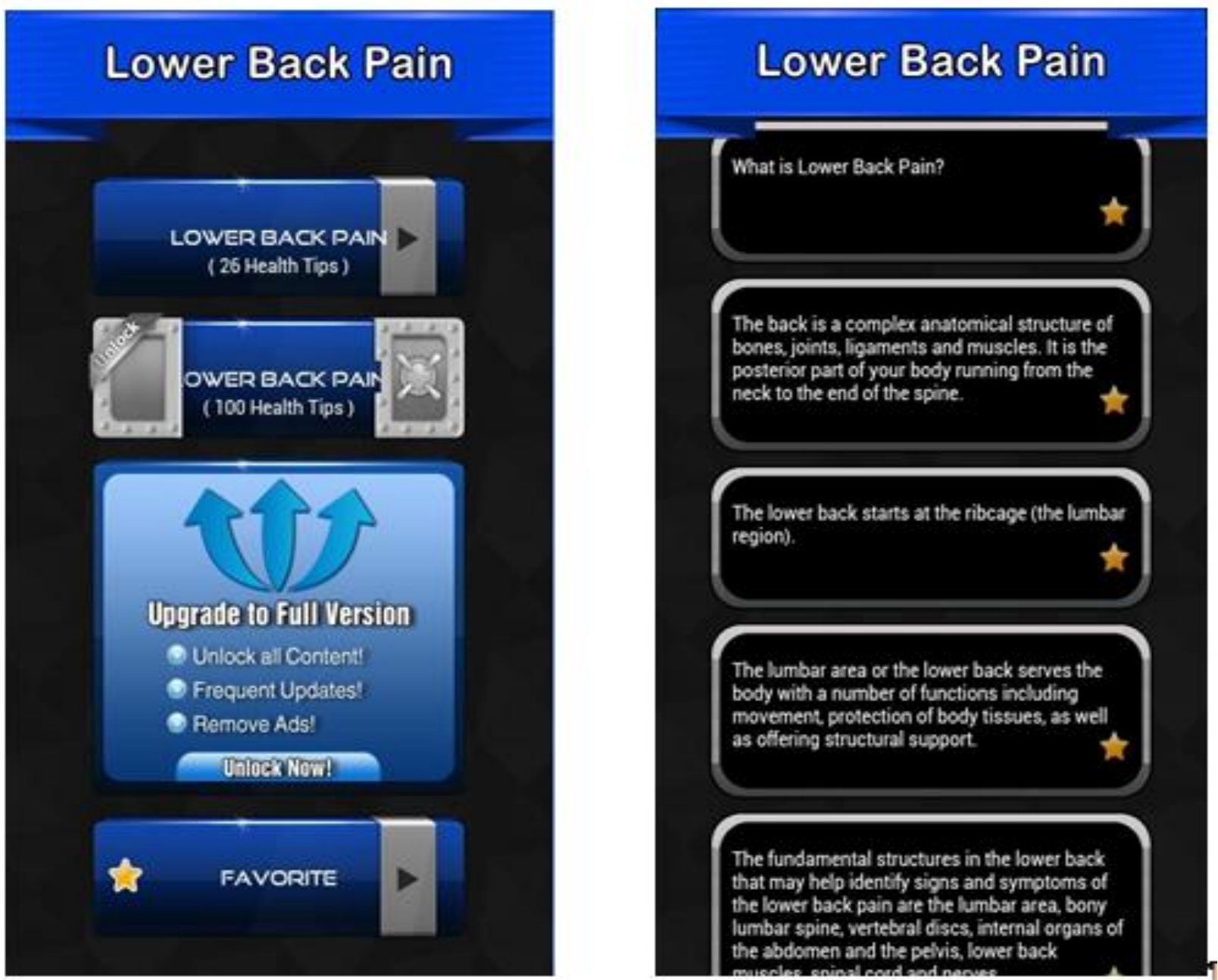

Figure 2.0: The interface of Lower Back Pain application

Lower Back Pain is an application that spreads from lower back torment's definition, lower back torment causes, lower back torment side effects and data identifying with lower back agony. This application (see Figure 2.0) can help client in lessening lower back torment

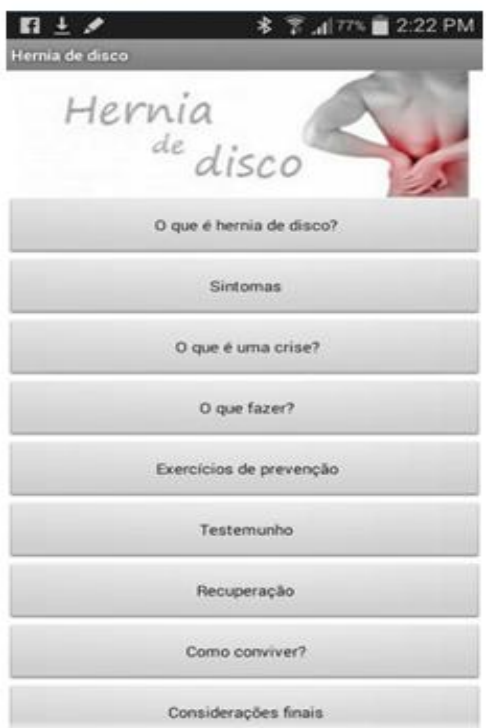

issues. In any case, there is no intelligence components that can connect the client to continue utilizing this application. The interface of this application is dull, not appealing, not well compose and the interface configuration is awful.

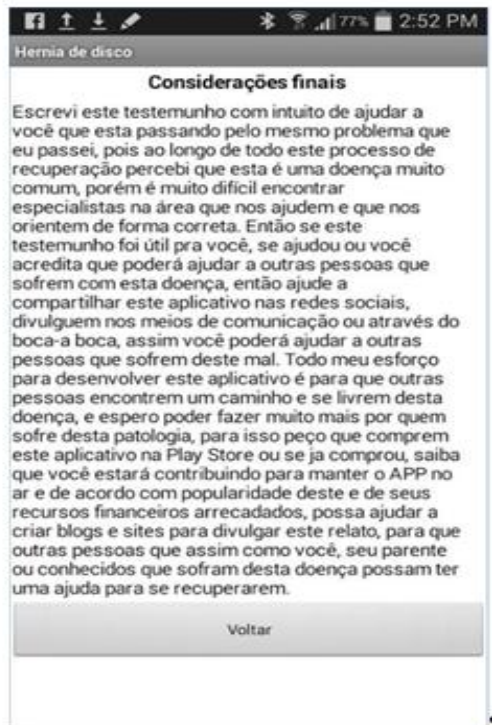

Figure 3.0 The interface of Hernia de Disco (Ajuda) application

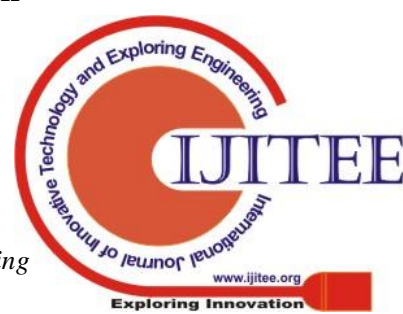


Hernia de Disco (discern 3.zero) a Spanish restorative health utility was created a good way to help people experiencing slipped circle, it provide the information, realities and widespread pointers for sufferers of slipped plate. the difficulty with this utility is the language utilized in this software. This software applied Portuguese language and it isn't applicable to Malaysian tradition. This utility utilizes a much mandate enlightening application without combined media intelligence, (for example, visuals or sound) that may be applied to choose up the keenness of the customers to this utility. As referenced by Fowler, intelligence may be notion of as shared pastime among the student, the getting to know framework, and the gaining knowledge of cloth (Lawrence, 1996).

Tragically, there is as but inaccessible edition of Malaysian Hernia (Slipped Disk) portable programs human offerings. this will incorporate Malaysian related therapeutic well being statistics on Hernia Disk which covers a few components, for example, language, medicinal depiction, belief, treatment Malaysian emergency clinics and so on. in this way, with the advancement of various flexible programs, it is essential to parent out which are usually beneficial. advent has guided with improvement and enterprise of the programs and frameworks portrayed. The those who construct restorative devices and programming packages required a domain that helps disclosure and advent. This consists of a lifestyle which encourages development and recommendations that assist designers benefit coins from different manifestations.

versatile innovation gives explicit strategies to assist with special administrations. introduction is a number one part of the cycle considering the fact that it's miles hard to fabricate system or building programming with out a extensive state of affairs which energizes and rewards creativeness. Policymakers energize the utilization of cellular phones for human offerings. these devices spread hastily in different nations and speaks to a noteworthy hazard to alternate the way of how medicinal consideration is conveyed. The innovations furnishes the ability to interface sufferers with experts and empower wellbeing, onitoring that recommends progressed the commitment and improve wellbeing results. versatile improvements can direct in giving get right of entry to for facts, faciliating far flung attention and increment in efficiencies. versatile wellness digital products and administrations changed into a widespread element in medicinal services assets around the world.

\section{ADDIE VERSION COURTING (SLIPPED DISK)}

The intervals of this model include research, plan, advancement, execution, and evaluation for the techniques of the exploration, this venture will make use of the ADDIE model to show off the exercises of the exam; the ADDIE model is a traditional and disentangled instructional framework structure (ISD) version. have a look at has picked this model since it places an extremely good accentuation on breaking down the difficulty and structuring a powerful association that tops off the holes that is diagnosed at the exam prepare. This model additionally will lead the exploration fact in the direction of giving excellent arrangements that could make a fantastic effect execution. The ADDIE model is fundamentally a traditional, orderly, well ordered shape utilized by academic creators, engineers and coaches to assure path development and studying does no longer appear in an aimless, unstructured manner. it's miles supposed to guarantee: college students will accomplish the targets of the social coverage path (Slipped Disk), takes into consideration the assessment of student's needs, the plan and advancement of getting ready materials, and evaluation of viability of the well-being content utility utilising forms with explicit, and quantifiable results. parent 5 underneath demonstrates the method of (ADDIE) model and its connection toward the improvement of Hernia Disk versatile utility. The model plan changed into adjusted from Gagne et al. (2005) which ADDIE version clarifies the huge ranges inside the development of flexible innovation packages. Likewise, the want viewpoints, for example, the substance, learning hypothesis and mastering structures are taken into consideration in dissecting records and structuring referring to Hernia or Slipped Disk content. The scientists connected the constructivist and moderation hypothesis as a chief component of studying hypothesis. whilst loose and adaptable mastering approaches are implanted in the software in the course of the making plans and development stage (Nawi et.al, 2015).

The exploration tool and extensive wellspring of information applied for this research is thru polls review which offer critical records. The approach utilized during this exploration are normally makes use of combined technique approach. The number one component include of quantitative research configuration covered conferences polls had been dispersed amongst 20 respondents. The inquiries are meant to meet the goal of this investigation, that is whether the consumer acknowledgment of portable software stage as their reference point in getting statistics about the slipped circle. The language applied in the ballot are for the most part English. The surveys had been based into three sections. In location A, the respondent had been requested the person profile, similar to sexual orientation and guides. location B predicted them to deal with the inquiries regarding the degree of studying and commentary approximately slipped plate amongst Malaysian subculture. In vicinity $\mathrm{C}$, the deliberate inquiries have been to understand the acknowledgment of purchasers seeing transportable utility stage as their reference factor in getting information approximately the slipped plate sickness. except, some other examination have been diagnosed to pay attention on additives which imparts among the event issue approximately slipped plate among Malaysia society information and their discernment closer to slipped circle in Malaysia.

For subjective data method, it makes use of speak with session. The meeting was used to verify discoveries from the ballot just as triangulate the records amassing techniques. five respondents had been associated with the meeting. five inquiries have been installation after convention with a few specialists within the theme quarter. The meetings further investigated approximately slipped plate sickness. The reason that this research uses mixed

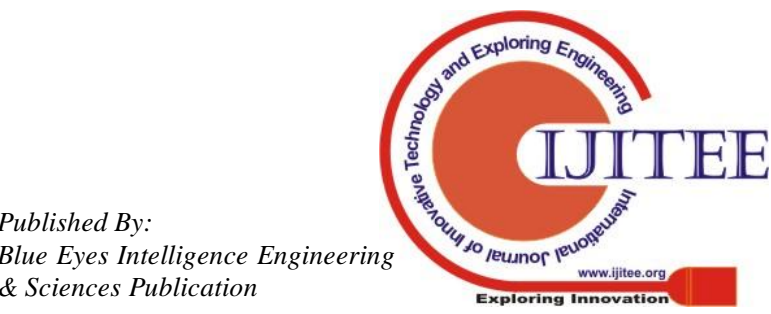


strategy configuration is to present a superior comprehension of slipped plate both quantitative or subjective unbiased from all people else. The usage of subjective strategies is compelling to get the nitty gritty statistics to present top to backside comprehension of an exploration trouble. The combination of quantitative and subjective discoveries can explain and extend the comprehension of the examination difficulty (Creswell \&Clark, 2007). This progression estimates the viability and execution of the aides. evaluation have to took place at some stage in the whole academic plan process internal, among, and after execution tiers. At lengthy closing, the evaluation of summative drew nearer is being applied which often takes place after the ultimate form of the aides is done. This assessment type decided the overall adequacy of the guide. Date from summative evaluation is usually used to come to a decision desire about the manual will either continue/stop steerage (Steven, 2000).

\section{PROTOTYPE DEVELOPMENT \& RESULTS}
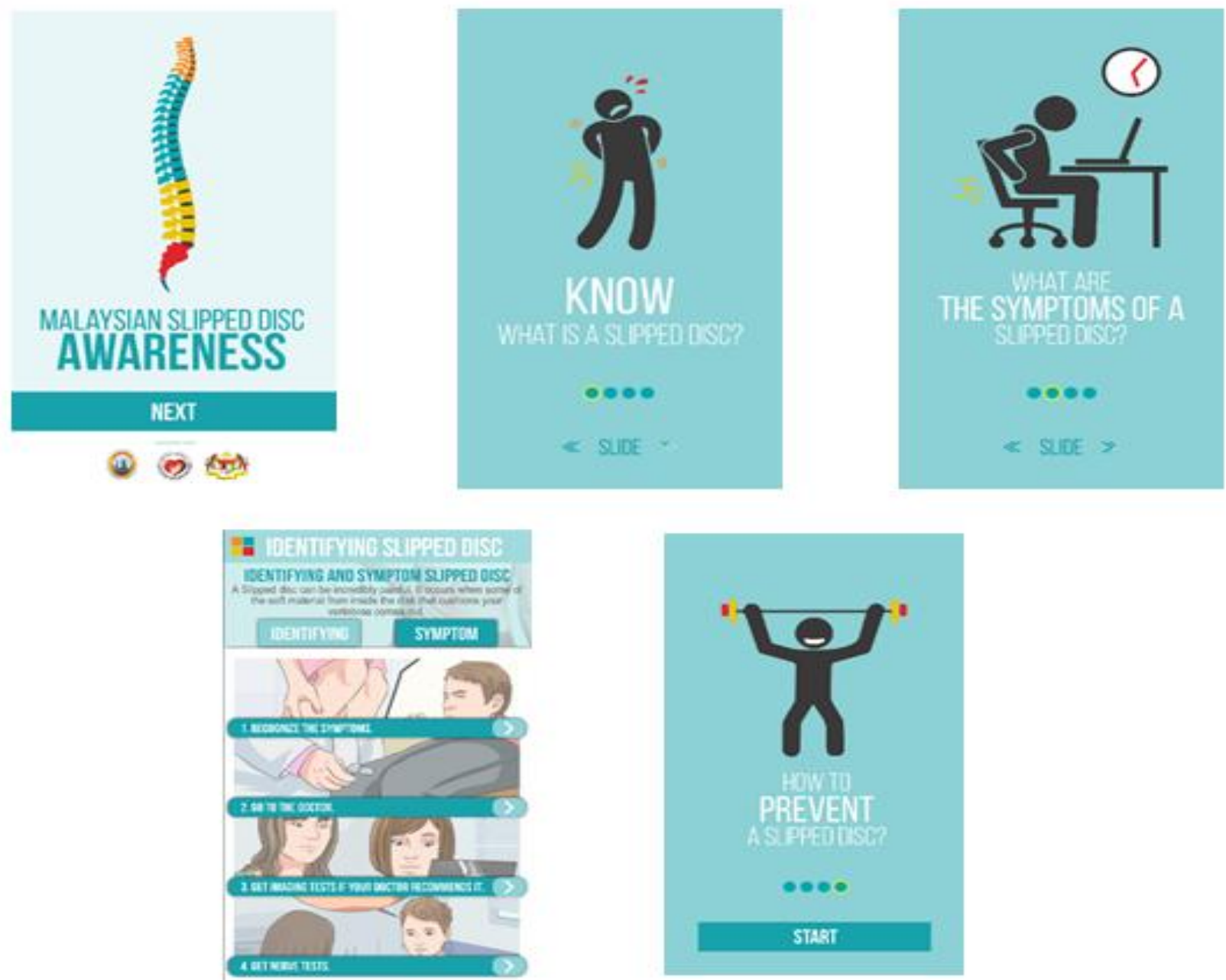

Figure 4.0 Sample M-Health User Interface (UI) Related to Malaysian Slipped Disc Awareness

as a way to make the Malaysian Slipped Disk attention (MSD) packages fruitful, prototyping procedure go as effortlessly as should fairly be predicted, the predominant issue that ought to be tended to is the diploma of fidelity to be able to be applied throughout the method. version is an example of the object inside the starting intervals of improvement. version is a time period utilized for an item or article earlier than it's far absolutely created. customers will try the version and give criticism with the goal that the object to be created to deliver a respectable object. making a model is intended to enhance all lacks at the item with the discoveries which have been made. With an unmistakable arrangement of client objectives and highlights diagnosed with MSD, we started mapping out every collaboration inclusive of the essential visual route which offers feed, substance and menu willpower. The shape system or person Interface (UI) as appeared in discern 4.zero; were in accordance with the substance and goal element (Malaysian grown-ups) prerequisite to accommodate M-health Malaysian Slipped Disk (MSD) user Interface (UI) specifically factors, as an instance, colours, textual styles (typography), design and so on. Be that as it can, we had constrained time which incapable to put a whole lot of foundation with the UI.

as a substitute the more a part of time was spent on drawing and envisioning out the middle highlights and emphasizing through the wireframes the fundamental associations. Likewise, we include enlightening updates and provide statistics approximately occasional instructive, updates, or inspirational advices to Malaysian lifestyle on awareness of Slipped Disc(MSD) illness. At remaining, for

Published By: 
the programming or returned-cease manner we use ActionScript (AS) 3.zero is the maximum recent model of Adobe Flash's customizing language that guarantees higher security, usefulness and proficiency. For the development process, we related AS programming (see discern 5.0) as a method to make any type of motion, improvement, pastime and sound to be able to make the MSD programs all of the more engaging with widely along with intuitive usefulness.

\section{DISCUSSION}

facts from this limited example of Slipped Disk health application customers gift self-management by using wellness purchasers with lower-returned soreness conditions may be upgraded thru usage of transportable programs. This wellknown research is to mixture these models, benefits of which include regular situation-specific measurements, as an example, specializing in wellness and records innovation talent, simply as usefulness, dedication and information the executives. additionally, extra profundity recognizing ease of use troubles whilst investigating consumer communique with self-administration targets via wellbeing packages become experienced whilst becoming a member of these 3 fashions. The Slipped-Disk portable utility likewise gives a refreshed gadget to assess wellbeing software comfort. As affirmed by one investigation, well being conduct is excessively mind boggling and multi-faceted for one version to cowl drastically

The Malaysian subculture via and massive are certain in the direction of the exertion in advancing the transportable programs for Slipped Disk. The utility had the choice to make another setting of versatile wellbeing packages which offers loads of data from analysis to counteractive motion approach. mobile telephones show guarantee as gadgets for conveying health facts and assisting customers address their wellbeing. wellness information was the quickest developing substance type in cellular telephone use in 2011 (Mirzai et al., 2007)

We receive the want to contain well being skillability into the improvement of mHealth or cell fitness packages is getting to be vital or simple fear amongst Malaysian health society. The primary Malaysian Slipped Disk M-wellness portable software mission show how consolidating well being education strategies for the duration of the improvement technique makes powerful packages. regardless of the truth that the software task contextual analysis talked about above featured processes to plot well being talented transportable packages, non-stop discourse and paintings on this area is needed. next stage is to incorporate the improvement of an appraisal instrument to decide the diploma to which a mHealth utility is wellness educated. We assume directing examination to display the effect of well-being talented mHealth packages on cease customers' frames of mind, getting to know, convictions, and conduct identified with health facts is likewise large. together, an appraisal tool and research should goad similarly coordination and improvement around well-being proficiency standards in mHealth software plan. At long final, as innovation and mHealth packages continue to broaden and alternate, more wellness education techniques or standards might be predicted to help engineers in coordinating health proficiency. get admission to and usage of mHealth programs is on the ascent. We agree with one method to enhance the functionality of elevating mHealth programs to enhance health is to assure that these programs are meant to carry well being statistics which highlight on easy get admission to, connecting with, protection, portability and training stages in particular u . s . a . regions. version a large part of the medicinal terms, or information (, for example, Slipped Disk or Hernia) are base on English definition and it'd task mainly amongst Malaysian rustic lifestyle zones states, for instance, (Kedah, Kelantan or Terengganu) to realize the healing phrasing such as warning signs, conclusion, treatment, drug and so forth. another part of the humanism and mind technological know-how of rustic networks is the reasonable feeling of conduct requirements which convert into community views on social jobs and elements of different individuals from the network. In severa countries, the social jobs and capacities are upheld via a protracted convention and express spiritual practices. individuals in united states of america networks (Malaysia) often esteem in all respects profoundly authoritative opinion or reasoning, as an instance, independence, self assurance and freedom, mixed with an apathy which comes basically from the cultivating society.

there's especially an emphasis on taking care of business. as a consequence, well-being is given an exceptionally low want which regularly converts into the view that medicinal administrations and emergency clinics definitely are the very last retreat. (Strasser, 2003)

making use of evidence - primarily based well being education methodologies to the development of mHealth applications is one manner greater people around the world can enhance their wellbeing through clear, noteworthy data and easy to-explore cell phones. For Malaysia, the accentuation is on allowing natives to play a steadily dynamic task in their personal well-being. inner its 4pronged method, Malaysia's medicinal services machine incorporates urging residents to end up more and more aware of the situation in their personal well-being and to take in more beneficial manner of lifestyles sports. some other want is enticing networks to execute singular wellness applications. with reference to making use of versatile innovation to deliver social insurance, the favorable function for international locations, as an instance, Thailand and Malaysia is that citizens realize about utilizing their telephones for a scope of administrations that as of now stretch out an extended ways past voice and instant message. 
transportable infiltration is excessive the various natives of these countries, because of this acknowledgment of mHealth, (as an example, Slipped Disk awareness among Malaysian way of life) is probably going to be excessive. expanding records switch capacity likewise empowers them to utilize propelled administrations, together with video, and the similarly advanced mobile phones can twofold as medicinal devices (Telenor and Boston, 2012)

\section{END}

transportable advances furnishes the ability to connect sufferers with experts and empower wellbeing gazing utilizing time wherein proposes to advanced patient dedication and advanced wellbeing outcomes. versatile well being appliences and administrations are turning a big things at stretch human services assets around the globe. besides, revolutionary assumes the precept job in most people of the flexible health packages. Designers becoming a member of the records of programming and device, just as the complexities of the medicinal services framework to make objects which could help people and suppliers in tending to scientific problems.

\section{REFERENCES}

1 Age well. (c2012). The star online. Recovered three March, 2016, from http://www.thestar.com.my/way of lifestyles/well being/2012/08/19/painintheback/4. Incontent material reference: (Age well, c2012)

2 Balagué F, Mannion AF, Pellisé F and Cedras-chi C. Non-explicit low lower back torment. Lancet 2012; 379 : 482-491

3 Pavlov, Paul An., and David W. Stewart. (2000)," Measuring the results and Effectiveness of Interactive marketing: A research agenda" magazine of Interactive advertising, Vol (eleven). p.98-102

4 Holzer, An., and Ondrus, J. (2009, April). patterns in flexible application advancement. In international conference on cell wireless Middleware, running systems, and applications (pp. fifty five-64). Springer Berlin Heidelberg

5 Darrell M.West (2013, October). enhancing fitness Care thru cell medical devices and Sensors, center for technology improvements at Brookings, p.1-thirteen

6 Lawrence J.N. blended media records and getting to know. (1996). Diary of instructional Multimedia and Hypermedia (1996) five (2), 129-a hundred and fifty

7 Gagne, R.M., bet, W.W., Golas, okay.G. and Keller, J.M. (2005). requirements of instructional structure. Toronto, ON: Thomson Wadsworth

8 Nawi, A., Hamzah, M. I., Ren, C. C., and Tamuri, A. H. (2015). Reception of portable innovation for showing readiness in improving displaying nature of educators. prevalent magazine of education, eight(2), 113-124.

9 John W. Creswell, Vicki L. Plano Clark. making plans and carrying out combined strategies studies (2010,June) SAGE publications, Inc; second model

10 Steven J McGriff. (2000). instructional system layout (ISD): using ADDIE model. instructional structures, college of education, Penn nation college.

11 Mirzai H, Tekin I, Yaman O, et al. The aftereffects of nucleoplasty in sufferers with lumbar herniated plate: an imminent scientific investigation of 52 continuous patients. spine J. 2007 Jan-Feb. 7(1):88-ninety two; conversation 92-three

12 Teleno.Boston group, (2012). on line resource : http://www.telenor.com/morethan/wp-content
material/transfers/2016/06/THE-SOCIO-financial-effectOF-cellular-health-\%E2\%80p.c93-MALAYSIA-

THAILAND-.pdf

13 Strasser R. (2003). Rustic health around the world: demanding situations and answers. circle of relatives practice; Vol. 20: P.457-463 